\title{
An Informative Study of Project Management Constraints
}

\author{
Usman Ali Khan \\ Department of IS- FCIT, King Abdulaziz University, Jeddah, Saudi Arabia
}

\begin{abstract}
In a fast speed of change in technology, it is very difficult "doing more with less resources", less cost with higher quality requires smarter planning and new concepts to help your projects succeed. Project management is the applications of various areas including, knowledge, skills, tools and techniques to project activities to meet project requirements. It offers various benefits, such as better control of the resources, lower costs and higher quality. It play an important role for businesses and it is vital to run projects in successful manner within the priority wise constrains. The constraint theory of Project management is the identification, definition, categorization, utilization, modification, planning, implementation, and control of project constraints. Constraints may be grouped into categories. In this theoretical paper a comprehensive study propose project management constraints classification on priority basis to ensure positive outcomes.
\end{abstract}

Keywords: Project management, Triple Constraints

\section{Introduction}

Project manager has to balance the competing factors like Scope, Time, and Cost along with quality. It is the Project Manager's duty to balance and achieve theses oftencompeting goals. Triple constraint is an eminent and esteemed mechanism used by the project managers to designate the major elements of a project. It (triple constraint)should be considered a strength not a liability to the project manager. An able manager should be well acquainted with its usefulness, its application and ramification. Project constraint management and a new project management category of constraints were defined. The project managers can apply these positive concepts and creative approaches quickly and easily to new projects to ensure successful outcomes. [1]

As simple as it seems, except three constraints can often be overlooked, underestimated and even incomplete. More often than not, only one or two constraints are identified on a project and the delivery team is left with the responsibility to fill in the blanks on any control not specifically defined up front. [2]

Time - time signifies the real duration needed to make a product which is the outcome of the project. Verily, the time span to produce the goods is correlated with the cost and the final produce of the project.

Cost - the evaluation of the monetary requirements to finish the project is the cost of the project. It incorporates various other items also, as materials and supplies, labor rates of contractor, risk calculation, and so on. Therefore, anything related to the financial expenditures forms a part of the cost structuring.

Scope - it is an operational element of the project which is indispensable and required to make the final product ready to deliver which is the aim of any consignment.

Generally, the scope is taken into account in advance to ensure the successful completion of the project. As per the requirement of the project, the scope varies or can be adjusted even during the project. This phenomenon is known as "scope-creep". And the measure of its success is the quality of deliverables. The term 'triple constraint' has been derived from a reason that if one constraint is changed or disturbed the other two are directly influenced. For instance, if one extends the scope making twenty webpages from the proposed ten, so evidently more time and money is required to get the necessary outcome. The noteworthy point is that the triple constraint is a triangle like entity. One side cannot be changed without disturbing the other two sides. Therefore, if the scope requires changes during the ongoing process, the time and cost would automatically be influenced. On the basis of aforementioned instances there arises a big question on part of the manager that how would he stay on top? or what would be the course of action to guarantee the successful outcome amid the mentioned circumstances?[3]

\section{Fathom the very concept of Triple Constraints}

The core is the awareness of the manager. He should be well-acquainted with the fact that time, cost and scope, the three major elements of any project are interdependent. If any of these elements get disturbed. If any of these elements get disturbed the others will be affected. Sometimes the project manager is unconscious about midway changes and its consequences on the final project. Such ignorant conditions may lead to project failures.

\section{Communicate the Concept of Triple Constraints}

After understanding the concept of triple constraint it should be communicated further with the other stakeholders of the project. By doing so the result will be favorable, and the decisions regarding the time, scope and cost will be easy to make. As the stake holders are responsible for 'scope-creep' or monetary adjustments in the project, they should be kept well informed in-advance. The follow-up meetings, the dialogues over the outcome and the investigations of the changes will be painless and straightforward. It is advisable to share the triple constraint to the beneficiaries at the very beginning of the project to enable its smooth running till it finally ends.[4] 


\section{Supervision of the Triple Constraints}

For the favorable outcome of the project, the project manager should make sure that he has the best of all the three attributes of triple constraint. He should keep himself well-informed of all sorts of alterations and shifts in time, cost and scope. He should confirm that change in one will in turn affect the other two aspects.

\section{An enhance project management constraints approach}

As we know that the market condition is uncertain because of rapid speed of change in the technology. Therefore any time during the project there are changes in a project. Consequently manager need to manage all constraints simultaneously otherwise the project is going to be risky.As triple constraints are not enough for managing a current project. Out of all ten knowledge area's sixof them should be on the top priority managing the project like Scope, Time,Cost, Resource, Risk, and Quality. The aforementioned constraints are independent, change in one vibrates the rest. And managing them in a way so that one gets the desired result is not a cake walk. For example if the prerequisites are unavailable, the time limit should be extended. Project cost will also be affected if the other unavailable resources costs more than the previous ones. If the quality assurance people do not approve the quality of the product then additional resources would be required. It raises the cost further and the time as well, in such situations of scope-creep, time and cost of the project rises and the quality may be substandard.

\section{Quality}

This attribute is related to scope with a slight disparity.

Scope is the desired final result while quality is the character or nature of the same result. For example, if the desired end result is to get ten webpages, these ten webpages has nothing to do with quality. It's the number of words that each webpage should have decides its character. If the word limit is 1000 pages with a quality tolerance of +/- 100 words, 900 words can be accepted while 850 can be rejected.Quality is also dependent on time. If the deadline is near, one compromises with the quality of the end product

\section{Risk}

This attribute is related to control the unpredictable results and minimize the uncertainties during the project is the most crucial task for project managers. Let's assume the assignment is to create a wireframe for a website. Within the time limit the manager ignores the client review and finishes the webpages. The risk is the possibility of rejection of final webpage from the client. This should be handled tactfully. If the manager wants to avoid this risk altogether then it will affect the cost as well as time.

\section{Resources}

Resources affect the cost of the project directly. The financial estimate restricts the purchase of resources. But sometimes even the sufficient amount of finances won't be enough as the specific resource needed for the project can't be received at the desired time. Eventually the project goes beyond the deadline. Therefore, if the resource is essential for the assignment one has to sacrifice the deadline.

\section{Customer Satisfaction}

How to meet the level of expectation of the customer? If all the three constraints were well followed with maximum efficiency the customer would surely be satisfied. If the finances go beyond the limits one might be compelled to withdraw. Thus customer satisfaction is directly related to the success of the project. [5]

\section{Tool to Handle Customer Satisfaction}

There is no set formula to satisfy the customer. So do communicate with them regularly for their feedback. The progress of the project can also be discussed with them from time to time. Ask them if they need more information and transparency. Their suggestions should also be welcomed.

\section{Priority wise categorization of knowledge area's}

All knowledge area are important for managing the project, no one can be ignore but as per priority it can be categorized as following [6]

- First Category: Scope, Time \& Cost

- Second Category: Quality, Risk \& Resource

- Third Category: Communication, Procurement, Stakeholder \& Integration

\section{Potential Negative Risk conditions associated with each knowledge area}

- Inappropriate planning, inadequate resources, improper management, negligence in reviewing the project after its completion

- Undefined scope or work packages

- Miscalculation in time and availability of resources, directing the critical area, improper control of float, untimely delivery of best reasonable products

- Wrong calculation of expenditure, produce, change and incidental expenses

- Inappropriate attention towards the quality of the end product, low quality material, and craftsmanship, insufficient value assurance program

- Poor conflict management; poor project organization and definition of responsibilities; absence of leadership

- Negligence in organization and communication

- Being oblivious of the risk, poor risk analysis, and substandard insurance management

- Unenforceable conditions or contract clauses; adversarial relations

- No transparency with the with the main stakeholders [7]

\section{Conclusions}

In the past days, the project managers use to reflect only three constraints, which are scope, time and cost. Nevertheless, considering only triple constraints are not good enough in today's practice of project management. Therefore it's decisive to know all constraints of a project. The best way to control them is to understand them. So when making important decisions, don't just consider only triple constraints scope, time and budget, but also other remaining constraints like quality, risk, resources, sustainability, organization, methodology and customer satisfaction. Consequently balancing all the constraints on the basis of their priority throughout the project management is exigent to make successful project. 


\section{References}

[1] Kozy, K. (2010). PM constraint theory-a new category of constraints to ensure positive outcomes. Paper presented at PMI® Global Congress 2010-Asia Pacific, Melbourne, Victoria, Australia. Newtown Square, PA: Project Management Institute. website: http://www.pmi.org/Marketplace/Pages/Product Detail.aspx?GMProduct $=00101081200 \&$ iss $=1$

[2] Goldratt, E. (1999). The theory of constraints. Great Barrington, MA: North River Press Publishing.

[3] Project Management Institute. (2004). Practice standard for earned value management. Newtown Square, PA: Author.

[4] Usman Ali Khan "How do project managers evaluate and plan for R \& D Project" International Journal of Innovative Research in Computer Science \& Technology (IJIRCST) ISSN: 2347-5552, Volume-6, Issue-6, November-2018

[5] Thomas, J., \& Mulley, M. (2008). Researching the value of project management. Newtown Square, PA: Project Management Institute.

[6] Usman Ali Khan \& S.F. Haider, "Impact of quantitative analysis techniques in enhancing Time Management, International Journal of Innovative Research in Engineering \& Management", ISSN: 2350-0557, Volume-4, Issue-5, September-2017

[7] Project Management Institute. (2008). A guide to the project management body of knowledge $\left(\right.$ PMBOK $^{\circledR}$ Guide) - Fourth edition. Newtown Square, PA: Author.

\section{Author Profile}

Usman Ali Khan is an Associate Professor in the Information Systems Department, Faculty of Computing and Information Technology, King Abdul Aziz University, Jeddah, Saudi Arabia. $\mathrm{He}$ received Ph.D. degree in Software Engineering, from the Integral University, India and working in the field of research and teaching at graduate and undergraduate level since 1995. He has published many research papers at national and international forums. 